\title{
Analysis of diversity using simple sequence repeat (SSR): distinctions between original Parmentiera cereifera tree and somaclones
}

\author{
Adel Ahmed Elshafei ${ }^{1^{*}}$ (D) and Naglaa Mohamed Esmaiel ${ }^{2}$
}

\begin{abstract}
Background: The possibility of culturing Parmentiera cereifera in vitro was tested. Shoot tips and lateral buds were cultured in three media that were based on Murashige and Skoog (MS) but supplemented with different types and concentrations of growth regulators. Thirty-eight simple sequence repeat (SSR) primers were used to assess the genetic stability of the regenerated plantlets.

Results: Lateral buds recorded the highest significant mean values for shoot, root length, and the number of leaves when cultured in MS + $1.2 \mathrm{mg} / \mathrm{l}$ of 6-benzylaminopurine (BAP) $+1.5 \mathrm{~g} / \mathrm{l}$ of activated charcoal. Seeds were also grown in different media. The best results were obtained with MS basal medium. The resulting shoots were rooted in MS medium, with $1.5 \mathrm{~g} / \mathrm{l}$ of activated charcoal. Regenerated plants were acclimatized in the greenhouse. The 38 SSR primers produced 63 scorable bands ranging from 1 to 3, with an average of 1.68 per primer. Fifty-five monomorphic bands were obtained that ranged from 0 to 3, with an average of 1.45 per primer. The coefficient of similarity matrix ranged from 0.92 to 1.0 , with an average of 97.4. Dendrogram generated using the SSR data tended to group the in vitro plants with the mother plant into two major clusters. The first cluster contained 19 in vitro plants with the mother plant and consisted of 4 subgroups. The second cluster contained in vitro plants, P-15, which had the lowest genetic similarity (92\%) with the mother plant.
\end{abstract}

Conclusions: The results revealed the increase in the degree of similarity between the tested plants in the SSR analyses. Therefore, micropropagation is a safe mode for multiplication of true-to-type plants of $P$. cereifera.

Keywords: Parmentiera cereifera, MS medium, Regenerated plants, In vitro diversity, SSR

\section{Background}

Parmentiera cereifera (candle tree) belongs to the Bignoniaceae family and is a small tree native to Panama. The leaves are oblong and acuminate. The flowers are white, slightly fragrant, and emerges directly on the bark of the tree. The fruits are smooth, waxy skinned green-yellow, and resemble candles. The tree is grown as an ornamental for its flowers and unusual appearance (van Steenis 1977; Madulid 2000). Previous studies have highlighted the anticancer properties, in addition to its anti-inflammatory, cardioprotective, and antimicrobial properties by flavonoids, saponins, tannins, triterpenoids, terpenoids, and steroids in

\footnotetext{
* Correspondence: elshafei_2000@yahoo.com

${ }^{1}$ Genetics and Cytology Department, Genetic Engineering and Biotechnology Division, National Research Centre, Al-Behoos Street, Dokki, Cairo 12622,

Egypt

Full list of author information is available at the end of the article
}

the leaves, barks, and fruits (Reyad-ul-Ferdous et al. 2012; Reyad-ul-ferdous et al. 2014a; Reyad-ul-ferdous et al. 2014b and Reyad-ul-ferdous et al. 2015). In Egypt, propagation of this tree is very challenging, and only two Parmentiera cereifera trees remain throughout the country (Theresa 2010). Plant tissue culture technology may have the potential to solve such problems.

In vitro culture has been mostly used for the propagation and preservation of genetic resources in ornamentals (Engelmann 2011; Rout et al. 2006). In addition, in vitro propagation is also a powerful tool for the conservation of trees, including rare and endangered species (Saha et al. 2012; Agarwal et al. 2015). Thus, in order to preserve such a valuable genotype, it is essential to increase the genotypic diversity and use micropropagation techniques to address challenges in species with longer lifecycles. However, maintaining the genetic stability of 
the line is also important, which forms the basis of this study. The continued use of in vitro propagation techniques brings the risk of inducing genetic variability, namely somaclonal variation. Clonal variation can be distinguished by DNA fingerprinting using variable types of markers such as simple sequence repeat (SSR). SSRs are generally effective and consistent when used for detecting genetic uniformity (Rahman and Rajora 2001).

Genetic stability of different micropropagated plantlets is evaluated by different markers such as random amplified polymorphic DNA (RAPD) and inter simple sequence repeats (ISSR) (Rani et al. 1995; Rout et al. 2001; Martins et al. 2004; Ray et al. 2006; Sathyanarayana et al. 2008; Bhatia et al. 2011; Saha et al. 2012; Anand et al. 2013; Agarwal et al. 2015). DNA from 23 micropropagated plants of a single clone of Populus deltoides were amplified using 11 RAPD primers. Of these, 5 were able to generate 30 polymorphic bands common across 6 micropropagated plants. Aside from these six plants, the amplification products were monomorphic in all the micropropagated plants (Rani et al. 1995). Ten SSR loci were used to study 17 micropropagated plantlets. Thirty somaclones of 1 tree and 4 somaclones of another tree were derived from 3 different Populus tremuloides donor trees (genotypes) from 8 of the 10 SSR loci, in which, no microsatellite DNA variation was observed among the 30 somaclones (Rahman and Rajora 2001). Using 12 RAPD primers in 15 micropropagated and mother plants of Paulownia tomentosa (Rout et al. 2001), no variation was found among the micropropagated plants.

Micropropagation and validation of genetic homogeneity of Alhagi maurorum and Pittosporum eriocarpum using start codon targeted polymorphism (SCoT), ISSR, and RAPD markers were reported by Agarwal et al. (2015) and Thakur et al. (2016). They used these markers to confirm the genetic homogeneity of seven tissue-cultured plantlets from their parent. The amplification products were monomorphic in all the seven micropropagated plants as well as the mother plant as per SCoT, ISSR, and RAPD (Agarwal et al. 2015). In another study, SCoT, ISSR, and RAPD markers were used to validate the genetic homogeneity of nine Pittosporum plantlets produced in vitro with their parent. DNA validation of the in vitro regenerated plantlets revealed monomorphic bands similar to the parent. The similarity values ranged from 0.89 to 1.00 for SCoT, 0.91 to 1.00 for ISSR, and 0.95 to 1.00 for RAPD. Cluster analysis revealed $97 \%$ similarity among the micropropagated plants and the parent (Thakur et al. 2016).

Recently, the clonal fidelity of in vitro regenerated plants was assessed using ten RAPD and ten ISSR markers in sugarcane Co 86032 and Q117 cultivars (Thora et al. 2017). Analysis of the ten RAPD markers showed that 90.48 and $86.95 \%$ true-to-type plantlets were regenerated in Co 86032 and Q117, respectively. ISSR markers, on the other hand, did not reveal any polymorphism in Co 86032 and $92.18 \%$ true-to-type plantlets were found in Q117. This study aims to find a suitable protocol to regenerate Parmentiera cereifera, an endangered plant, throughout tissue culture technique, and also to assess the genetic stability of the regenerated plantlets using SSRs.

\section{Methods}

\section{Tissue culture experiments}

Shoot tips, lateral buds, and seeds of $P$. cereifera were obtained from one tree (only two trees exist in entire Egypt), grown in the Antoniades gardens, Smouha, Alexandria, Egypt (Fig. 1a). The explants were surface sterilized in $75 \%$ ethanol for $1 \mathrm{~min}$, followed by rinsing with $0.1 \%$ mercuric chloride for $10 \mathrm{~min}$ and washing thoroughly six times with sterile distilled water. The vegetative explants were cultured in Murashige and Skoog $(\mathrm{MS})+1.2 \mathrm{mg} / \mathrm{l} \mathrm{BAP}+1.5 \mathrm{~g} / \mathrm{l}$ activated charcoal or MS $+2.5 \mathrm{mg} / \mathrm{l}$ of BAP $+1.25 \mathrm{mg} / \mathrm{l}$ of kinetin or $\mathrm{MS}+$ $1.5 \mathrm{mg} / \mathrm{l}$ gibberellic acid (GA3) $+1.5 \mathrm{~g} / \mathrm{l}$ activated charcoal and incubated for 4 weeks under controlled conditions $\left(25 \pm 2{ }^{\circ} \mathrm{C}\right.$ and $16 / 8$ dark/light cycle in a growth chamber). Seeds were germinated in media listed in Table 1 and incubated for $16 \mathrm{~h}$ with illumination (2000 lx daylight fluorescent tubes) at $25 \pm 2{ }^{\circ} \mathrm{C}$ for 4 weeks. The resulting shootlets from all the tested explants were transferred to a basal MS medium supplemented with $1.5 \mathrm{~g} / \mathrm{l}$ activated charcoal for an additional 4 weeks for rooting (Fig. 1b). After the shoots and roots had developed, the regenerated plants were washed with tap water to remove the agar from the roots (Fig. 1c) and were transplanted to small pots filled with peat moss and perlite $(1: 1 v / v)$. The pots were incubated under moist conditions in the greenhouse for adaptation (Fig. 1d). Data were analyzed as a completely randomized design (CRD) experiment with ten replicates, and according to Steel and Torrie (1980). Mean values were compared using the least significant differences test (LSD). The data were analyzed using SAS program version (1985).

\section{DNA extraction}

Genomic DNA extraction of end cervical samples was performed using Wizard Genomic DNA Purification Kit (Promega Biotechnology Corporation, Madison, USA). The extracted DNA samples were treated with RNase, and stored at $-20{ }^{\circ} \mathrm{C}$ until further use.

\section{SSR analysis}

Thirty-eight SSR primers (Gupta et al. 2002) were used in the study (Table 3). A polymerase chain reaction 

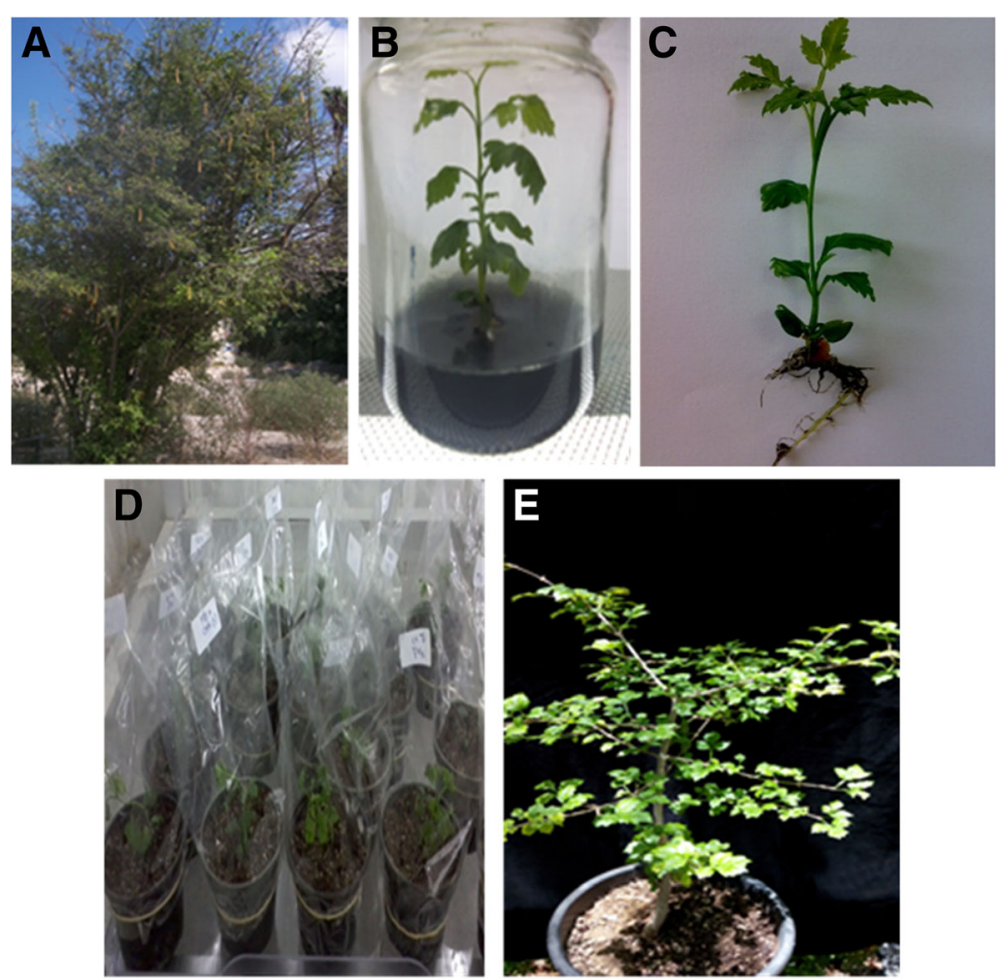

Fig. 1 a Mother tree. b Shoot formation. c Regenerated plants. d Whole plant established in the greenhouse

(PCR) reaction mixture consisting of 20-50 ng of genomic DNA, $1 \times$ PCR buffer, $1.5 \mathrm{mM} \mathrm{MgCl}_{2}, 0.1 \mathrm{mM}$ each dNTP, $0.5 \mu \mathrm{M}$ primer, and $1 \mathrm{U}$ Taq polymerase in a volume of $0.025 \mathrm{~cm}^{3}$. The PCR cycle for the SSR experiments included an initial denaturation at $94{ }^{\circ} \mathrm{C}$ for 3 min followed by 35 cycles of denaturation at $94{ }^{\circ} \mathrm{C}$ for $1 \mathrm{~min}$ annealing at 51 or $61{ }^{\circ} \mathrm{C}$ (depending on the individual microsatellite primer) for $1 \mathrm{~min}$, and extension at $72{ }^{\circ} \mathrm{C}$ for $2 \mathrm{~min}$ followed by a final extension at $72{ }^{\circ} \mathrm{C}$ for $10 \mathrm{~min}$. Amplification products were electrophoretically resolved using a $3 \%(\mathrm{~m} / \mathrm{v})$ agarose gel containing $0.1 \mu \mathrm{g} \mathrm{cm}^{3}$ ethidium bromide, and photographed on a UV trans-illuminator.

Table 1 Means of shoot, root length (cm), and leaves number, as influenced by media protocols of buds

\begin{tabular}{llll}
\hline Medium protocol & $\begin{array}{l}\text { Shoot } \\
\text { length }\end{array}$ & $\begin{array}{l}\text { Root } \\
\text { length }\end{array}$ & Leaves No. \\
\hline $\begin{array}{l}\text { MS }+1.2 \mathrm{mg} / \mathrm{l} \mathrm{BAP}+1.5 \mathrm{~g} / \mathrm{l} \\
\text { activated charcoal }\end{array}$ & $11.52 \mathrm{a}$ & $7.74 \mathrm{a}$ & $7.12 \mathrm{a}$ \\
$\begin{array}{l}\mathrm{MS}+2.5 \mathrm{mg} / \mathrm{l} \mathrm{BAP}+1.25 \mathrm{mg} / \mathrm{l} \\
\text { Kineti }\end{array}$ & $9.85 \mathrm{~b}$ & $8.03 \mathrm{a}$ & $6.85 \mathrm{a}$ \\
$\begin{array}{l}\text { and MS + 1.5 mg/l GA3 + 1.5 g/l } \\
\text { activated charcoal }\end{array}$ & $8.76 \mathrm{~b}$ & $7.41 \mathrm{a}$ & $7.23 \mathrm{a}$ \\
\hline
\end{tabular}

Means followed by the same letter are not significantly different at 0.05 level
Data handling and cluster analysis

SSR data were scored for computer-based analysis based on the presence of amplified products for each primer pair. If a product was present in 1 of the 20 micropropagated plants and the parent plant, it was designated as '1.' If absent, it was designated as '0,' after excluding the non-reproducible bands. Pairwise comparisons of the 20 micropropagated plants and the parent plant were made for the genetic similarity analysis. Jaccard's coefficient of similarity was used. A dendrogram was generated on the basis of clustering using the unweighted pair group method of the arithmetic averages (UPGMA). Principal coordinated analysis (PCA) was performed to show the distribution of the accessions in a scatter plot using PAST software version 1.62 (Hammer et al. 2001).

\section{Results}

Tissue culture experiments

Our experiments with the shoot tip explants did not yield much data because in all the media tested, they turned brown and died. The lateral buds, as discussed in Table 1, indicated the significant influence of media composition on the shoot length. The highest mean value recorded was $11.52 \mathrm{~cm}$ when the stable explants were cultured in MS medium + $1.2 \mathrm{mg} / \mathrm{l}$ 6-BAP + $1.5 \mathrm{mg} / \mathrm{l}$ activated charcoal. The remaining two media 
were found to not affect the shoot length. Concerning the root length, there were no differences observed due to difference in media composition. With regard to the number of leaves, there were no differences observed due to difference in media composition. For in vitro seed germination, data as shown in Table 2 revealed that the maximum mean value of the shoot length $(3.63 \mathrm{~cm})$ was obtained in MS basal medium. Also, MS and $3 / 4 \times$ strength MS were found to be superior compared to the other tested media, and recorded the highest significant mean values for root length $(5.45$ and $5.15 \mathrm{~cm}$, respectively). For the number of leaves, the highest mean value (5.5) was obtained when the seeds were incubated in MS basal medium.

\section{SSR analysis}

Thirty-eight SSR primers produced a total of 64 reproducible and scorable bands at an average of 1.68 bands per primer (Table 3). Two primers did not produce any band with the in vitro generated DNA clones. A total of 1324 scorable bands were generated from all combinations of the SSR markers and plantlets and only 60 (4.49\%) were polymorphic among the micropropagated plants. This reveals that the micropropagated $P$. cereifera is genetically stable (Table 3 and Fig. 2). Each primer produced amplification products in the range of 100400 bp (Table 3 and Fig. 2). All banding profiles from the micropropagated plants were monomorphic and parallel to the parent plant, except for nine primers; viz., primer SSR $2,6,8,9,16,18,20,22$, and 36 , which produced polymorphic bands in the regenerated plants. The number of scorable bands varied from one to three for each primer, as shown in Table 3.

The similarity value based on Jaccard's similarity coefficient was calculated for SSR markers in the 20 micropropagated plants and the parent. The results showed that the similarity ranged from 0.92 to 1 (Fig. 3). The dendrogram generated through UPGMA analysis revealed a $97.4 \%$ similarity among the regenerated plants and the parent plant. Dendrogram generated using SSR data grouped the in vitro grown plants along with the parent plant as two main clusters (Table 3 and Fig. 3).

Table 2 Means of shoot, root length (cm), and leaves number as influenced by media protocols of seeds

\begin{tabular}{llll}
\hline Medium protocol & Shoot length & Root length & Leaves No. \\
\hline N6 basal medium & $1.72 \mathrm{c}$ & $4.22 \mathrm{~b}$ & $3.8 \mathrm{~b}$ \\
NN basal medium & $2.05 \mathrm{c}$ & $4.28 \mathrm{~b}$ & $1.8 \mathrm{C}$ \\
MS basal medium & $4.63 \mathrm{a}$ & $5.45 \mathrm{a}$ & $5.5 \mathrm{a}$ \\
3/4 strength MS medium & $3.01 \mathrm{bc}$ & $5.15 \mathrm{a}$ & $1.6 \mathrm{C}$ \\
1/2 strength MS medium & $1.93 \mathrm{C}$ & $4.34 \mathrm{~b}$ & $2.1 \mathrm{C}$ \\
1/4 strength MS medium & $1.82 \mathrm{C}$ & $3.30 \mathrm{C}$ & $1.8 \mathrm{C}$ \\
\hline
\end{tabular}

Means followed by the same letter are not significantly different at 0.05 level
The first cluster contained 19 in vitro plants and the parent, which consisted of 4 subgroups. The first subgroup included four plants generated via the in vitro method; i.e., P-8, P-1, P-3, and P-2. The micropropagated plants (P-1 and $\mathrm{P}-3$ ) were $100 \%$ identical to the parent. A second subgroup included four plants generated via the in vitro method along with the parent plant, namely $\mathrm{p}-14, \mathrm{p}-12$, parent plant, $\mathrm{P}-19$, and $\mathrm{P}-17$. The micropropagated plants showed that $\mathrm{p}-12$ and $\mathrm{p}-19$ were very identical to the parent. A third subgroup included five plants generated via the in vitro method, namely P-7, P-9, P-10, P-16, and P-8, of which the micropropagated plants include P-9, P-10, and P-16. A fourth subgroup included six plants generated via the in vitro method, i.e., P-2, P-4, P 5, P-6, P-11, and P-13, of which the micropropagated plants include: P-4, P-5, P-6, and P-11, which were $100 \%$ identical to the parent. The second cluster contained plants generated via the in vitro method, P-15, which had the lowest genetic similarity (92\%) to the parent.

The dendrogram was confirmed by principal coordinate analysis (PCA) (Fig. 4). The PCA accounted for $1.61 \%$ of all variations. This is a slight variation observed compared to the similarity data obtained through SSR. Accessions in the PCA scatter plot indicated by ellipses and numbered with $\mathrm{A}$ (included all the plants generated via the in vitro method with the parent, except for $\mathrm{p}-15$ ) and B (includes only p-15) seemed to form a very close cluster in the dendrogram (Fig. 4). Accessions clustered in ellipses A and B were basically from groups I and II of the dendrogram, respectively. The PCA performed based on the SSR data set has depicted the genetic status and association of in vitro grown plants to the parent much more precisely (Fig. 4).

\section{Discussion}

\section{Tissue culture response}

Our results indicate that MS medium was effective for culturing either the lateral buds or germinating the seeds of P. cereifera. Nas and Read (2001) reported that iron source in the MS medium had a significant effect on shoot length and leaf color. In addition, shoots formed in the medium containing Sequestrene ${ }^{\circ} 138 \mathrm{Fe}$ (200 $\mathrm{mg} \mathrm{L}^{-1}$ ) were healthy and dark green. Further, activated charcoal was considered the most important factor to customize this medium, which was the best. Activated charcoal has been used in tissue culture as a source to improve the growth and the development of plant cells. It is also helpful in micropropagation, orchid seed germination, somatic embryogenesis, synthetic seed production, rooting, stem elongation, etc.

Rani et al. (1995) used MS liquid medium supplemented with $0.2 \mathrm{mg} / \mathrm{l} \mathrm{IAA}$ and $0.2 \mathrm{mg} / \mathrm{l} \mathrm{BAP}$ for growing micropropagated plants of Populus deltoides. After 
Table 3 Amplification products generated with SSR markers among mother plant and in vitro raised plants

\begin{tabular}{|c|c|c|c|c|c|}
\hline Primers & Forward primer $\left(5^{\prime} \rightarrow 3^{\prime}\right)$ & Reverse primer $\left(5^{\prime} \rightarrow 3^{\prime}\right)$ & A & B & C \\
\hline SSR1 & GTGAGCAATTTGATTATACTG & TACCCTGATGCTGTAATATGTG & 2 & 2 & 0 \\
\hline SSR2 & TCTGGCCAGGATCAATATTACT & TAAGATACATAGATCCAACACC & 2 & 1 & 1 \\
\hline SSR3 & GGTCTTCTGGGCTITGATCCTG & TGTTGCTAGGGACCCGTAGTGG & 2 & 2 & 0 \\
\hline SSR4 & GAAACAGGGTTAACCATGCCAA & ATGGTGCTGCCAACAACATACA & 1 & 1 & 0 \\
\hline SSR5 & GAGGGTTCTGAAATGTITTGCC & ACGTGCTAGGGAGGTATCTTGC & 3 & 3 & 0 \\
\hline SSR6 & CTCATGAGTATATCACCGCACA & GACGCGAAACGAATATTCAAGT & 2 & 1 & 1 \\
\hline SSR7 & TTATCTTGGTGTCTCATGTCAG & TCGCAAGATCATCAGAACAGTA & 1 & 1 & 0 \\
\hline SSR8 & TCCAATCAATCAGGGAGGAGTA & GAACGCATCAAGGCATGAAGTA & 3 & 2 & 1 \\
\hline SSR9 & TTCTAAAATGTTTGAAACGCTC & GCATTTCGATATGTTGAAGTAA & 2 & 1 & 1 \\
\hline SSR10 & GTTITGTGATCCCGGGTTI & CATGCGTCAGTTCAAGTITI & 2 & 2 & 0 \\
\hline SSR11 & GTCCATATATGCAAGGAGTC & GTACTCTATCGCAAAACACA & 1 & 1 & 0 \\
\hline SSR12 & AATGTCATGCGTGTAGTAGCCA & AAGCGCACTTAACAGAAGAGGG & 1 & 1 & 0 \\
\hline SSR13 & GCCTCTAGGGAGAAAACTAACA & TCAAGATCATATCCTCCCCAAC & 3 & 3 & 0 \\
\hline SSR14 & ATAAAGCTGTCTCTITAGTTCG & GTITAACACATATGCATACCT & 2 & 2 & 0 \\
\hline SSR15 & AGTGGTAATGAGGTGAAAGAAG & TCGGTCGTATATGCATGTAAAG & 2 & 2 & 0 \\
\hline SSR16 & AACACAAAAGATCCAACGACAC & CAGTATAGAAGGATTTGAGAG & 3 & 2 & 1 \\
\hline SSR17 & TACCCGAATCTGGAAAATCAAT & TGGAAGCTTGCTAACTTTGAG & 1 & 1 & 0 \\
\hline SSR18 & TGCAGTTGCGGATCCTTGA & TAACCAAGCAGCACGTATT & 1 & 0 & 1 \\
\hline SSR19 & AGGGCTCTCTITAATTCTTGCT & GGTCTATCGTAATCCACCTGTA & 1 & 1 & 0 \\
\hline SSR2O & TCCTTGACCCCTTGCACTAACT & ATGGTTGGGAGCACTAGCTTGG & 1 & 0 & 1 \\
\hline SSR21 & GTATCTCACGAGCATAACACAA & GAAAGTGTATGGATCATTAGGC & 2 & 2 & 0 \\
\hline SSR22 & ATTाTCTCAAACACACCCCG & TAGCAGATGTTGACAATGGA & 2 & 1 & 1 \\
\hline SSR23 & ACGTATCCAGACACTGTGGTAA & TAATGGTGGATCCATGATAGCC & 1 & 1 & 0 \\
\hline SSR24 & GAGATTTGTTCATTTCATCTTCGCA & TATATTAAAGGTTAGAGGTAGTCAG & 1 & 1 & 0 \\
\hline SSR25 & GACGTCAAGAATCTTCGTCGGA & ATCTGCTGAGCAGATCGTGGTT & 2 & 2 & 0 \\
\hline SSR26 & GCTCAGATCATCCACCAACTTC & AGATGCTCTGGGAGAGTCCTTA & 2 & 2 & 0 \\
\hline SSR27 & AGTAATCTGGTCCTCTCTTCTTCT & AGGTAATCTCCGAGTGCACTTCAT & 1 & 1 & 0 \\
\hline SSR28 & CCAAATCTTCGAACAAGAACCC & ACCGATCGATGGTGTATACTGA & 2 & 2 & 0 \\
\hline SSR29 & GCTTAACAAAGATCCAAGTGGCAT & GTAAACATCCAAACAAAGTCGAACG & 1 & 1 & 0 \\
\hline SSR30 & CTCCATCTATTGAGCGAAGGTT & CAAGATGAAGCTCATGCAAGTG & 1 & 1 & 0 \\
\hline SSR31 & GTGGATAACATCATGGTCAAC & TACTTCGCACTAGATGAGCCT & 2 & 2 & 0 \\
\hline SSR32 & TCAGGCCATGTATTATGCAGTA & ACGACCAGGATAGCCAATTCAA & 2 & 2 & 0 \\
\hline SSR33 & AGTTATGTATTCTCTCGAGCCTG & GGTAACCACTAGAGTATGTCCTT & 1 & 1 & 0 \\
\hline SSR34 & GACATGTGCACCAGAATAGC & AGAAGAACTATTCGACTCCT & 2 & 2 & 0 \\
\hline SSR35 & GGAGCATCGCAGGACAGA & GGACGAGGACGCCTGAAT & 2 & 2 & 0 \\
\hline SSR36 & TGCGGTACAGGCAAGGCT & TAGAACGCCCTCGTCGGA & 1 & 0 & 1 \\
\hline SSR37 & ACAAAGGTGCATTCGTAGA & AACACGCATCAGTTTCAGT & 1 & 1 & 0 \\
\hline SSR38 & CCTGTTGCATACTTGACCTITT & GGAGTTCAATCTITCATCACCAT & 2 & 2 & 0 \\
\hline Total & - & - & 64 & 55 & 9 \\
\hline Mean & - & - & 1.68 & 1.45 & 0.236 \\
\hline Maximal & - & - & 3 & & 2 \\
\hline Minimal & - & - & 1 & & 0 \\
\hline
\end{tabular}

$\mathrm{A}=$ number of scorable bands $\mathrm{B}=$ monomorphic bands, $\mathrm{C}=$ polymorphic bands 


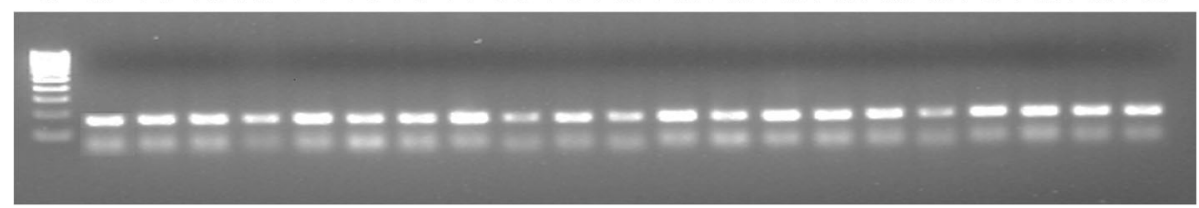

Fig. 2 The fragments obtained with primer SSR11, ladder, MP (mother plant), P-1 to P-20 plants generated in vitro

six passages using the multiplication medium, the propagules were transferred to hormone free MS medium for rooting. Sathyanarayana et al. (2008) found that a maximum of $6.70 \pm 1.15$ shoots with a mean shoot length of $1.07 \pm 0.21 \mathrm{~cm}$ were produced when MS medium supplemented with various concentrations of cytokinin was used. During the initial culturing with $3.5 \mu \mathrm{M}$ of 6-benzylaminopurine (BAP), a majority of the shoots $(5.17 \pm 0.04)$ had a mean length of $2.50 \pm 0.07$ when incubated in MS medium containing $1.0 \mathrm{mg} / \mathrm{l}$ of N6-benzyladenine (BA) in Ocimum gratissimum L (Saha et al. 2012). Hashish et al. (2015) found that explants with multiple shoots were found in the stem explants when grown in 3/4th strength MS medium and supplemented with BA at a concentration of $2 \mathrm{mg} / \mathrm{l}$, resulting in $100 \%$ survival of the explants. This media produced the maximum number of shootlets that were formed and the maximum number of leaves/explant. Thakur et al. (2016) reported similar observations in germinating seeds of Pittosporum eriocarpum. Using a different protocol established for micropropagation from nodal explants, high shoot regeneration (95\%) in MS medium supplemented with BA $0.4 \mathrm{mg} / \mathrm{l}$ and indole-3-butyric acid (IBA) $0.6 \mathrm{mg} / \mathrm{l}$ was observed. In vitro regenerated shoots were rooted in MS medium augmented with three auxins, of which $0.6 \mathrm{mg} / \mathrm{l}$ indole butyric acid was the best for rooting (90\%), resulting in a maximum number of roots per shoot. Using nodal explants cultured on MS medium enriched with $1.0 \mathrm{mg} / \mathrm{l} \mathrm{BA}$ and $0.5 \mathrm{mg} / \mathrm{l}$ NAA, shoot regeneration was high $(87.77 \%)$ with 4.77 shoots/explant, 2.27 shoot length (Saha et al. 2016).

\section{SSR analysis}

In this study, the results revealed that the 38 SSR primers yielded 64 scorable bands that ranged from 1 to 3 with an average of 1.68 bands per primer. The number of monomorphic bands were 55 , which ranged from zero to three, with an average of 1.45 bands per primer, as

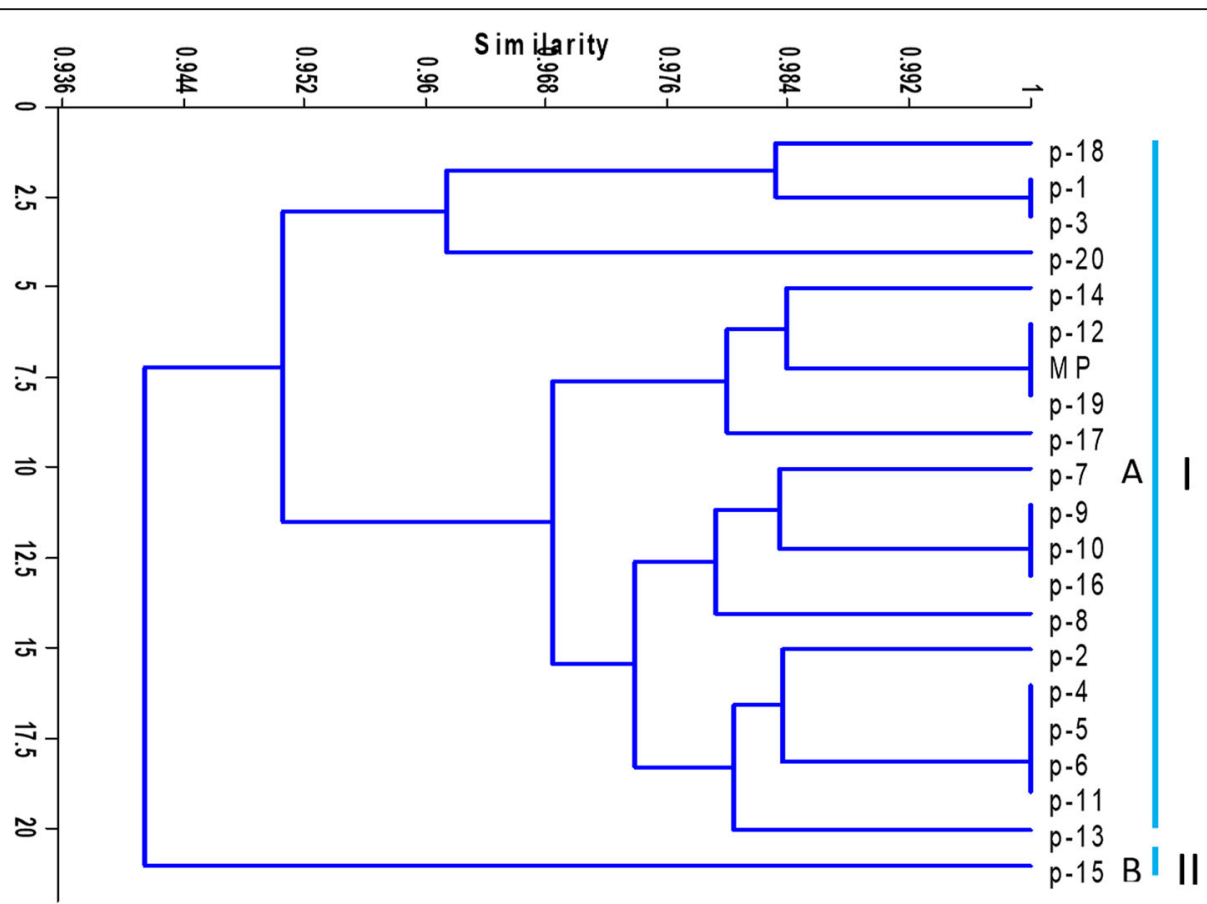

Fig. 3 Dendrogram showing the micropropagated plants and mother plants. Based on Genetic distance Method UPGMA (Jaccard 1908) 


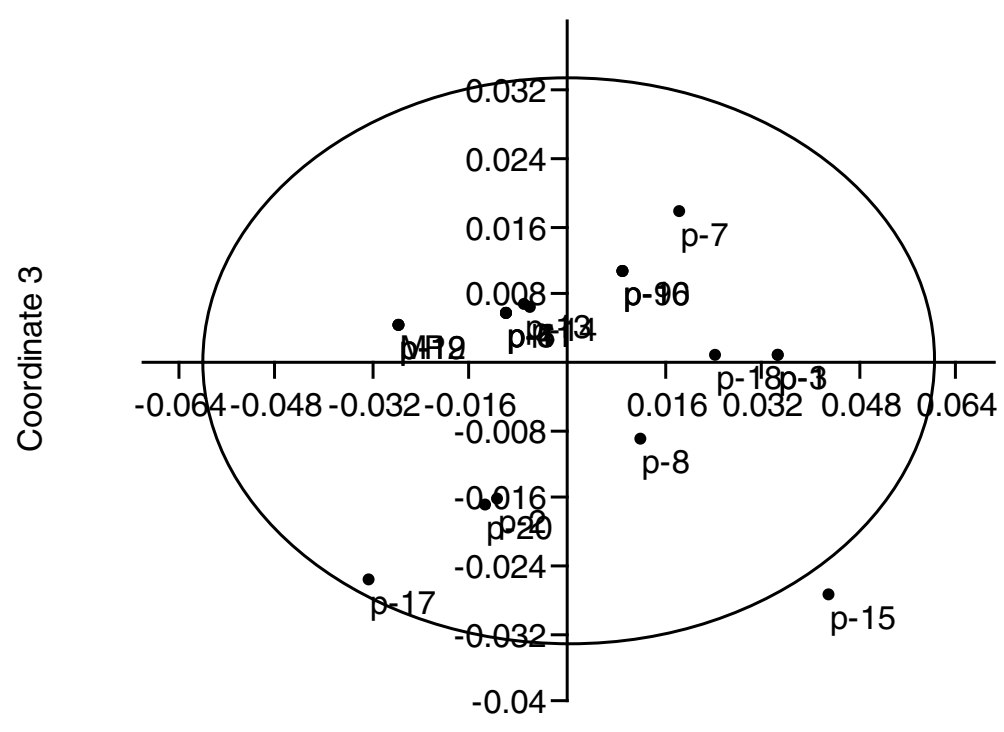

Coordinate 1

Fig. 4 The principal coordinate analysis (PCA) of SSR data from the micropropagated plants and mother plants

shown in Table 1. The coefficient of similarity matrix ranged from 0.92 to 1.0, with an average of 97.4. Previously, it was reported that the markers for genetic analysis were found in 23 micropropagated plants of Populus deltoids (Rani et al. 1995). Using 11 RAPD primers that amplified the DNA, 5 were able to distinguish a total of 13 polymorphisms common across the 6 micropropagated plants. Apart from these six plants, the amplification products were monomorphic in all the micropropagated plants. Our results are in agreement with those of Rahman and Rajora (2001) and Esmaiel et al. (2014), who observed no variations in the microsatellite DNA among the 13 somaclones of 1 tree and 4 somaclones of another tree at 8 of the 10 SSR loci in Populus tremuloides, and using ten SSR primers (Rahman and Rajora 2001 and Al-Murish et al. 2013). A total of 1309 scorable bands were obtained from the full combination of SSR primers and plantlets, of which only 98 (7.49\%) were polymorphic. This showed that the micropropagated Lagunaria patersonii is genetically stable. Many previous studies indicated the absence of genetic differences between parents and the micropropagated plants (Rout et al. 2001; Nanda et al. 2004; Bhatia et al. 2011; Saha et al. 2012; Esmaiel et al. 2014; Agarwal et al. 2015; Treviño et al. 2017). The genetic variability through random amplified microsatellite polymorphism (RAMP) visualized as a dendrogram did not reveal any variations between the parent and the micropropagated plants in Moringa oleifera (Treviño et al. 2017). However, some studies have reported high genetic similarities but with few genetic differences between the parent and the micropropagated plants (Rani et al. 1995; Rahman and Rajora 2001; Ray et al. 2006; Sathyanarayana et al. 2008; Esmaiel et al. 2014; Purohit et al. 2017). A total of 42 bands were observed and only 3 primers (OPA 20, OPJ 8 , and OPJ 17) produced polymorphic bands. The similarity matrix observed ranged from 90 to $97 \%$. The dendrogram indicated two different groups (groups I and II). Group I comprised $\mathrm{T}_{4}$ plants, and group II comprised all other tissue culture-raised plants $\left(\mathrm{T}_{1}\right.$ to $\mathrm{T}_{3}, \mathrm{~T}_{5}$ to $\mathrm{T}_{10}$ ) along with the parent, as indicated when using 12 RAPD primers in Amomum subulatum.

\section{Conclusion}

The results reveal a high degree of similarity between the plants when examined with SSR markers. Therefore, micropropagation can be deemed a safe mode for multiplication of true-to-type plants of $P$. cereifera. We found that SSR was effective in determining the degree of similarity between the plants produced in vitro and the parent. As a next step, we are considering using additional molecular markers to reconfirm our findings.

\section{Abbreviations}

BA: N6-Benzyl adenine; IBA: Indole-3-butyric acid; ISSR: Inter simple sequence repeats; KN: 6-Furfuryl aminopurine; MS: Murashige and Skoog; NAA: 1Naphthaleneacetic acid; PCA: Principal coordinate analysis; PCR: Polymerase chain reaction; RAPD: Random amplified polymorphic DNA; SCOT: Start codon targeted polymorphism; SSR: Simple sequence repeat; 2,4D: 2,4Dichlorophenoxyacetic

\section{Acknowledgements}

The authors thank the Deanship of Scientific Research and RSSU at King Saud University for their technical support. Great appreciations are also due 
to Prof. M.I. Shaalan, and Prof. m. Motawei, for their suggestions and proofreading this manuscript.

\section{Funding}

This study was funded by the authors' (A. A. Elshafei and N.M. E.)

\section{Availability of data and materials}

The authors declare that the experimental data and material are available.

\section{Authors' contributions}

A. A. Elshafei performed the analysis with the molecular markers. N.M. E. performed the tissue culture experiments. Both authors read and approved the final manuscript.

\section{Ethics approval and consent to participate}

The authors declare that the work is ethically approved and consent to participate.

\section{Consent for publication}

The authors declare that the work has been consented for publication.

\section{Competing interests}

The authors declare that they have no competing interests.

\section{Publisher's Note}

Springer Nature remains neutral with regard to jurisdictional claims in published maps and institutional affiliations.

\section{Author details}

${ }^{1}$ Genetics and Cytology Department, Genetic Engineering and Biotechnology Division, National Research Centre, Al-Behoos Street, Dokki, Cairo 12622, Egypt. ${ }^{2}$ Floriculture Department, Horticulture Institute, Agriculture Research Center, P.O. Box 21523, Alexandria, Egypt.

Received: 15 October 2018 Accepted: 26 November 2018

Published online: 19 December 2018

\section{References}

Agarwal T, Gupta AK, Patel AK, Shekhawat NS (2015) Micropropagation and validation of genetic homogeneity of Alhagi maurorum using SCOT, ISSR and RAPD markers. Plant Cell Tissue Organ Cult 120(1):313323 https://doi.org/10.1007/s11240-014-0608-z

Al-Murish TM, Elshafei AA, Al-Doss AA, Barakat MN (2013) Genetic diversity of coffee (Coffea arabica L.) in Yemen via SRAP, TRAP and SSR markers. J Food Agric Environ 11:411-416

Anand M, Brar J, Sood A (2013) In vitro propagation of an edible bamboo bambusa Bambos and assessment of clonal Fidelity through molecular markers. J Med Bioeng 2(4):257-261 https://doi.org/10.12720/jomb.2.4.257-261

Bhatia R, Singh KP, Sharma TR, Jhang T (2011) Evaluation of the genetic fidelity of in vitro-propagated gerbera (Gerbera jamesonii Bolus) using DNA-based markers. Plant Cell Tissue Organ Cult 104(1):131-135 https://doi.org/10.1007/ s11240-010-9806-5

Engelmann F (2011) Use of biotechnologies for the conservation of plant biodiversity. In Vitro Cell Dev Biol Plant 47(1):5-16 https://doi.org/10.1007/ s11627-010-9327-2

Esmaiel NM, Elshafei AA, Zakri AM, Al-Doss AA, Barakat MN (2014) Assessment of clonal fidelity of micro-propagated Lagunaria patersonii plants by TRAP and SSR markers. J Food Agric Environ 12(2):916-921

Hammer D, Harper A, Ryan P (2001) PAST: Palaeontological statistics software package for ducation and data analysis. Palaeontol Electronica 4:9

Hashish Kl, Taha LS, IbrahimS M (2015) Micropropagation potentiality and pigments content of hibiscus rosa-sinensis I. as affected by gamma radiation. Int J ChemTech Res 8(9):131-136

Jaccard P (1908) Nouvelles rechearches sur la distribution locale. Bull Soc Vaud Sci Nat 44:223-270

Madulid DA (2000) A Pictorial Encyclopedia of Philippine Ornamental Plants. 2nd ed. Makati City: Bookmark, Inc. p. 388

Martins M, Sarmento D, Oliveira MM (2004) Genetic stability of micropropagated almond plantlets, as assessed by RAPD and ISSR markers. Plant Cell Rep 23(7):492-496 https://doi.org/10.1007/s00299-004-0870-3
Nanda RM, Das P, Rout GR (2004) In vitro clonal propagation of Acacia mangium and its evaluation of genetic stability through RAPD marker. Ann For Sci 61: 381-386.

Nas MN, Read PE (2001) micropropagation of hybrid hazelnut: Medium composition, physical stat and iron source affect shoot morphogenesis, multiplication and explant vitality.5th Intl. Congr. On hazelnut. Acta Hort 556:251-258.

Purohit S, Nandi SK, Paul S, Tariq M, Palni LMS (2017) Micropropagation and genetic fidelity analysis in Amomum subulatum Roxb.: a commercially important Himalayan plant. J Appl Res Med Aromatic Plants 4:21-26 https://doi.org/10.1016/j.jarmap.2016.07.003

Rahman MH, Rajora OP (2001) Microsatellite DNA somaclonal variation in micropropagated trembling aspen (Populus tremuloides). Plant Cell Rep 20(6):531-536 https://doi.org/10.1007/s002990100365

Rani V, Parida A, Raina SN (1995) For genetic analysis in micropropagated plants of Populus deltoides Marsh. Plant Cell Reports 14:459-462

Ray T, Dutta I, Saha P, Das S, Roy SC (2006) Genetic stability of three economically important micropropagated banana (Musa spp.) cultivars of lower indo-Gangetic plains, as assessed by RAPD and ISSR markers. Plant Cell Tissue Organ Cult 85(1):11-21 https://doi.org/10.1007/s11240-005-9044-4

Reyad-ul-ferdous M, Md AH, Abdullah N, Mridulsarker FH et al (2014b) Preliminary in vitro phytochemical screenings of the barks of Parmentiera cereifera seem. Int J Innov and App Res 2:57-60

Reyad-ul-Ferdous, Md RBR, Sikder AA, FahimaAktarMd, Rashid MA (2012) Preliminary In Vitro Biological and Phytochemical Screenings of Parmentiera cereifera Seem. Bangladesh Pharm J 15:103-106

Reyad-ul-ferdous, Md TTA, Md Al, Khan Zl, FarihaTasnim, Md MEK, Ullah S, TazmelHaque (2015) Ex-vivo cardioprotective and cytotoxic screening of fruits of Parmentiera cereifera seem. Biol Med (Aligarh) 7:1

Reyad-ul-ferdous M, Anisul I, Md s, FarihaTasnim NA, TowshinAlam T et al (2014a) Qualitative phytochemical screenings of Methanolic extract of $P$. cereifera seem fruits. UK J Pharm Biosc 2:22-23

Rout GR, Mohapatra A, Jain SM (2006) Tissue culture of ornamental pot plant: a critical review on present scenario and future prospects. Biotechnol Adv 24(6):531-560 https://doi.org/10.1016/j.biotechadv.2006.05.001

Rout GR, Reddy GM, Das P (2001) Studies on in vitro clonal propagation of Paulownia tomentosa Steud. and evaluation of genetic fidelity through RAPD marker. Silvae Genetica 50(5-6):208-212

Saha S, Adhikari S, Dey T, Ghosh P (2016) RAPD and ISSR based evaluation of genetic stability of micropropagated plantlets of Morus alba L. variety S-1. Meta Gene 7:7-15 https://doi.org/10.1016/j.mgene.2015.10.004

Saha S, Kader A, Sengupta C, Ghosh P (2012) In vitro propagation of Ocimum Gratissimum L. (Lamiaceae) and its evaluation of genetic gidelity using RAPD marker. Am J Plant Sci 3(1):64-74 https://doi.org/10.4236/ajps.2012.31006

Sathyanarayana N, Bharath TN, Vikas PB, Rajesha R (2008) In vitro clonal propagation of Mucuna pruriens var. utilis and its evaluation of genetic stability through RAPD markers. Afr J Biotechnol 7(8):973-980

Thakur J, Dwivedi MD, Sourabh P, Uniyal PL, Pandey AK (2016) Genetic homogeneity revealed using SCOT, ISSR and RAPD markers in micropropagated Pittosporum eriocarpum Royle- an endemic and endangered medicinal plant. PLoS One 11(7):1-17 https://doi.org/10.1371/ journal.pone.0159050

Theresa L. 2010. Herbarium Orman botanical garden, Giza, Egypt. Personal communication

Treviño JA, Muñoz-Alemán JM, Pérez-Molphe-Balch E, Rodríguez-Sahagún A, Morales-Domínguez JF (2017) In vitro propagation from bud and apex explants of Moringa oleifera and evaluation of the genetic stability with RAMP marker. S Afr J Bot https://doi.org/10.1016/j.sajb.2016.10.003

Thora AS, Sonone NA, Choudhari W, Devarumath RM, Babu KH (2017) Plant regeneration from cell suspension culture in Saccharum officinarum $L$. and ascertaining of genetic fidelity through RAPD and ISSR markers. 3 Biotech 7(1):1-12

van Steenis CGGJ (1977) Bignoniaceae. In: Flora Malesiana ser. I, 8, pp 114-186 